\title{
BOLIVIA 2011: GOBERNANDO CON EL CONFLICTO
}

Bolivia 2011: Governing with the conflict

\section{GRACE I. DEHEZA}

Ministerio de Economía y Finanzas Públicas

\section{RESUMEN}

El año 2011 en Bolivia se caracterizó por ser uno de los años más conflictivos de la gestión del presidente Morales; entre estos conflictos están el gasolinazo, el conflicto por la defensa del TIPNIS y los conflictos sectoriales. En este año por primera vez en la historia se dieron las elecciones para Magistrados del Poder Judicial, elecciones que tuvieron irregularidades desde su inicio. Todos estos hechos afectaron al gobierno que a pesar de todo ha logrado mantener a la mayoría de sus aliados sindicales y logró introducir al sector del empresariado nacional como parte de apoyo a la Agenda Nacional.

Palabras clave: Bolivia, conflictos, TIPNIS, elecciones judiciales.

\begin{abstract}
The year 2011 was characterized as one of the most troubled years of the president Morales administration, due to the raise of price of the gas-oil or gasolinazo conflict, the defense of the TIPNIS' protected areas, and some other union's conflicts. For the first time in the history of Bolivia, elections for judges took place but the process had irregularities since its inception. All these events affected the government; nevertheless it had managed to maintain most of its union allies and was able to gain the support of the national private entrepreneurs to the National Plan.
\end{abstract}

Key words: Bolivia, conflicts, TIPNIS, judiciary elections. 


\section{COYUNTURA ECONÓMICA: LA RENTA DE LOS RECURSOS NATURALES}

El balance de la economía boliviana para el 2011 ha sido positivo, tal como muestran los informes económicos oficiales. Según del Ministerio de Economía y Finanzas Públicas el crecimiento del PIB proyectado para el 2011 es de 5,2\%, con un 1,4\% más que el PIB del año 2010. El crecimiento, como en años anteriores, se debe al incremento del sector de hidrocarburos, gas y petróleo y minería. El superábit del sector público no financiero se proyecta que estará en $0,8 \%$ como porcentaje del PIB y el Tesoro General de la Nación tendrá un déficit de $-0,5 \%$. La inflación acumulada a diciembre del 2011 fue de 6,9\%. ${ }^{1}$

La inversión directa extranjera después de la drástica reducción de los años 2003-2006 logró recuperarse ya a partir de 2007; durante enero y junio de 2011 la inversión neta fue de US $\$ 319$ millones de dólares, la cual fue superior en 63,7\% a la inversión durante el mismo periodo para 2010, aunque ésta todavía no alcanza los niveles registrados en el 2000. ${ }^{2}$ La inversión nacional privada alcanzó U\$S 1.100 millones de dólares, siendo superior a la extranjera. ${ }^{3}$

La inversión pública durante el 2011 subió en un 34\% con relación al año 2010; el sector de transportes tuvo la mayor asignación presupuestaria (803.4 millones de dólares), seguido de hidrocarburos (315.2 millones de dólares) y urbanismo y vivienda (293.7 millones de dólares). Como parte de la política del gobierno de distribución de las riquezas y del nuevo modelo de desarrollo del gobierno del presidente Morales, se mantuvieron como en años pasados los bonos Juancito Pinto, Renta Dignidad y Bono Madre-Niño Juana Azurduy. De la misma forma se continuó con la recreación de empresas públicas. ${ }^{4}$

\section{COYUNTURA SOCIAL: CONFLICTOS SOCIALES}

El 2011 se caracterizó por ser el año más conflictivo desde que Evo Morales entrara al gobierno. A pesar de los éxitos económicos y de las políticas de redistribución del gobierno del presidente Morales, según el Observatorio del Conflicto en el 2011 se registraron

1 Ministerio de Economía y Finanzas Públicas. 2011. “Indicadores Macroeconómicos”. [En línea] http://www. economiayfinanzas.gob.bo/index.php?opcion=com_indicadores\&ver=indicadores\&idc=564, [Consulta: 13-2-2012]

2 El flujo de la inversión extranjera directa fue en el sector manufacturero e hidrocarburos; la mayor parte constituye la reinversión de las utilidades. Es interesante notar que en este primer semestre las inversiones provenientes de España representaron el 30\% y Suecia el 18\%. Banco Central de Bolivia. 2011. "Reporte Semestral de Saldos y Flujos del Capital Privado Extranjero en Bolivia". Junio 2011. [En línea] http:/ /www. bcb.gob.bo/webdocs/2011/SalaDePrensa/otros/Reporte\%20I-2011\%20RSFVPE.pdf [Consulta: 30-2-2012]

3 La mayor inversión proviene del sector minero y construcción. Fuente: Cámara Nacional de Comercio. 2011. "Dos Años del Segundo Periodo del Gobierno de Evo Morales y el Compromiso de la Implementación de una Agenda Económica". Enero de 2012. [En línea] [ttp://www.boliviacomercio.org.bo/cnc/Documentos/ NP201202Enero.pdf. [Consulta: 30-2-2012]

4 Iván Arias realizó una evaluación publicada por la Fundación Milenio en diciembre del 2011; la respuesta a ese documento es: Ministerio de Desarrollo Productivo y Economía Plural. “Las Empresas Estatales en el Nuevo Modelo Económico de Bolivia". [En línea] http://medios.economiayfinanzas.gob.bo/MH/documentos/ Materiales_UCS/Libros/Libro_empresas.pdf [Consulta: 30-2-2012] 
884 eventos, cerca de 2,5 conflictos por día. ${ }^{5}$ Estos conflictos se dan por las demandas insatisfechas de los distintos sectores sociales y por los límites de las políticas estatales de redistribución de las rentas nacionales.

El primer gran conflicto se registró los últimos días de diciembre del 2010 hasta los primeros días de enero del 2011, cuando el presidente Morales tuvo que enfrentar la fuerte oposición al Decreto Supremo 748 emitido el 26 de diciembre de 2010.6 La medida, más conocida como "gasolinazo", incrementaba los precios de los combustibles; el gobierno pretendía nivelar los precios nacionales de los hidrocarburos a los precios de los países vecinos para evitar el incremento del gasto público en la subvención y para que no se fuera del país a través del contrabando. El precio de la gasolina por litro subía en $73 \%$ y de la misma forma el diesel subía en $82 \%$; el precio de gas licuado para consumo en hogares y para transporte no sufría variación. El impacto inflacionario de esta medida fue inmediato, los productos alimenticios subieron por la especulación en los mercados, la Confederación de Choferes, que reúne al gremio del transporte público, llamó a un paro indefinido, las tarifas del transporte subieron en $100 \%$, a pesar de que el gobierno autorizó un incremento sólo del 30\%.

El presidente Morales anunció una serie de medidas para mitigar los efectos del DS 748: incrementó los salarios en $20 \%$ para las fuerzas armadas, policía, educación y salud. No obstante, no pudo detener la escalada de manifestaciones en contra de la medida de los diferentes sectores sociales en las principales ciudades del Bolivia; algunos inclusive pedían la renuncia del Presidente. ${ }^{7}$ A cinco días de haber emitido la medida, el presidente Morales se vio forzado a derogar el DS 748. ${ }^{8}$ No obstante, a pesar de que logró calmar las protestas, esta medida dañó la imagen del gobierno y del Presidente. Sectores sociales aliados al presidente Morales pedían la destitución de los ministros Sacha Llorenti, Luis Arce y Nemesia Achacollo 9 por haber asesorado mal al Presidente. Como se verá más adelante, el Presidente realizó cambios en su gabinete ministerial, aunque mantuvo a los ministros cuestionados.

El segundo conflicto de mayor impacto para el gobierno fue el protagonizado por los indígenas de las tierras del sector del oriente boliviano que demandaban la no construcción de la carretera, tramo II, de Villa Tunari (Cochabamba) a San Ignacio de Moxos (Beni); este tramo cruzaría por el Territorio Indígena y Parque Nacional Isiboro Sécure (TIPNIS), zona protegida y reconocida como parque nacional desde 1990. Para los indígenas que habitan en la zona del TIPNIS, la construcción de la carretera implicaría de hecho la expansión de las plantaciones de coca y además causaría daños al medio ambiente en la

5 Citado por Fundación Milenio 2012. “Informe de Coyuntura Nacional”. N 132. Febrero 2012.

6 Gaceta Oficial del Estado Plurinacional de Bolivia. “Decreto Supremo 748”. [En línea] http:/ /gacetaoficialdebolivia. gob.bo/normas/view/138884 [Consulta: 13-2-2012]

7 El Mundo, 31 de diciembre de 2010. [En línea] http:/ / www.elmundo.com.bo/Secundarianew.asp?edicion=3 1/12/2010\&Tipo=Politica\&Cod=10944 [Consulta: 20-2-2012]

8 Evo Morales en su mensaje de abrogación del mencionado decreto indicaba que lo hacía porque había prometido "gobernar obedeciendo al pueblo".

9 Los Tiempos, 2 de enero del 2011. [En línea] http:/ / www.lostiempos.com/diario/actualidad/economia/20110102/ morales-el-cambio-de-ministros-es-mi-atribucion_106671_208787.html [Consulta: 20-2-2012] 
zona. El gobierno desatiende la solicitud presentada por el sector indígena del TIPNIS y acusa a los dirigentes indígenas de ser instrumento de la oposición. ${ }^{10}$ Los indígenas habitantes del parque, con el apoyo de la Confederación de Pueblos Indígenas de Bolivia (CIDOB) y del Consejo Nacional de Ayllus y Markas del Qullasusyu (CONAMAQ) iniciaron una marcha en defensa del TIPNIS. A pesar de los intentos de desprestigio desde el gobierno, la marcha continuó en dirección a la sede de gobierno demandando entablar un diálogo con el Presidente. En su paso los marchistas sufrieron varios intentos de bloqueo por los colonizadores, ahora llamados interculturales. Los colonizadores apoyaban la propuesta del gobierno de construcción de la carretera porque, según ellos, el tramo los beneficiaría. Ese sector movilizó a la Federación Chimoré, Mamoré, Carrasco, Yungas, Chapare, la Federación del Trópico ${ }^{11}$ para apoyar la construcción de la carretera. No obstante, la sección de la Federación Provincial de Colonizadores de Caranavi se separó del movimiento colonizador y apoyó a los marchistas del TIPNIS.

El 25 de septiembre en la zona de Yucumo se dio el más duro intento para desarticular la marcha indígena con el uso de la fuerza policial; un contingente de 500 policías gasificaron el campamento de los indígenas en presencia de niños y mujeres, hubo heridos, detenidos; las mujeres, niños y algunos dirigentes huyeron para no ser detenidos. Las imágenes del uso de la fuerza policial conmovieron a la ciudadanía, dando su apoyo al sector movilizado. Los marchistas varios días después se reagruparon y partieron desde Quiquibey hacia la ciudad de La Paz, a lo largo de su camino los indígenas fueron recibidos con apoyo de los moradores. La llegada a la ciudad de La Paz coincidiría con las primeras elecciones judiciales de octubre de 2011; sin embargo, los marchistas retrasaron su llegada a la ciudad de La Paz para no interrumpir el proceso electoral y para mostrar que este movimiento no tenía ninguna intención política de bloquear al gobierno. A su llegada el 18 de octubre, la ciudadanía paceña de todos los sectores recibió a los marchistas. ${ }^{12}$

En todos los departamentos distintos sectores sociales organizaron marchas y manifestaciones en apoyo al movimiento del TIPNIS; hubo la demanda por identificar a los responsables de la orden de represión al movimiento. El gobierno enfrentó su segunda crisis de gabinete, el ministro de Gobierno Sacha Llorenti y la ministra de Defensa Cecilia Chacón renunciaron a sus cargos, la segunda por no estar de acuerdo con la represión. También otros dos altos directivos del gobierno, el viceministro de Régimen Interior y Gobierno, Marcos Farfán, y la directora de Migración, María René Quiroga, el primero para dar paso a la investigación y la segunda también por no estar de acuerdo con la represión. 
Pero la crisis llegó al Parlamento, donde cinco diputados indígenas del MAS veían la posibilidad de dejar ese partido. ${ }^{13}$

La respuesta del presidente Morales se dejó esperar, pero ante la presión ciudadana y las implicaciones en la erosión del apoyo de los sectores indígenas no tuvo otra alternativa que dar un paso atrás promoviendo un proyecto de ley de prohibición de la construcción de la carretera. El proyecto fue aprobado en el Congreso y la ley fue promulgada el 25 de octubre. No obstante, este conflicto no se ha solucionado, el gobierno ha planteado la necesidad de una consulta entre las poblaciones que defienden la protección del TIPNIS y de los pobladores que defienden la construcción. Estos últimos realizaron una marcha para demandar su construcción, marcha que no tuvo ningún escollo en su llegada a La Paz, ni despertó la adhesión de la ciudadanía en general.

Este conflicto ha puesto de relieve las diferencias entre el movimiento indígena, los sectores sindicales cocaleros, colonizadores y los sectores indígenas de las tierras altas y bajas. Las organizaciones indígenas de CIDOB y de CONAMAQ, que le dieran apoyo al presidente Morales y fueran miembros de la Coordinadora Nacional por el Cambio (CONALCAM), se alejaron del gobierno, mientras que otros sectores del movimiento indígena mantienen su apoyo. ${ }^{14}$

El gobierno también tuvo que afrontar los conflictos sectoriales por el incremento de salarios con los trabajadores de salud y magisterio. Además los jubilados y las personas discapacitadas demandaron del gobierno un incremento a sus rentas.

En los últimos años, los límites de los municipios han creado conflictos entre los municipios y pobladores de las zonas afectadas. Según el anteproyecto de Ley de las Unidades Territoriales, de los 339 municipios que existen en el territorio nacional solamente 25 cuentan con una definición clara sobre sus límites territoriales. La falta de una definición de los límites municipales ha creado conflictos entre los municipios de la ciudad de La Paz, de Cochabamba y también a municipios de los departamentos de Oruro y Potosí.

Evo Morales enfrentó movilizaciones, manifestaciones y marchas por demandas sectoriales, a excepción de las limítrofes, conflictos que han mermado la imagen del Presidente, como evidencian los sondeos de opinión pública realizados mensualmente por IPSOS Apoyo, Opinión y Mercado en el eje troncal de Bolivia (La Paz, El Alto, Cochabamba y Santa Cruz). La figura 1 muestra que el presidente Morales inició el año 2011 con altos niveles de desaprobación en enero (56\%) y en febrero $(63 \%)$ a causa del gasolinazo. La aprobación del Presidente sube de abril a julio, pero nuevamente llega a niveles considerablemente altos de desaprobación en septiembre y octubre a raíz de los conflictos por el TIPNIS y por su accionar durante el proceso de las elecciones judiciales.

13 Cargagen, Pedro Nuni, Justino Leaños, Cristina Valeroso y Bienvenido Zacu. El Sol 27 de Septiembre de 2011. [En línea] Blanca http://www.elsol.com.bo/index.php?c=pol\%EDtica\&articulo=Repud io-por-el---Tipnis\&cat $=150 \&$ pla $=3 \&$ id_articulo $=21139$

14 Los sectores que son más afines al gobierno son el movimiento de mujeres Bartolina Sisa, algunos sectores de la CONAMAQ y la CSUTCB, estos sectores asistieron en diciembre al Encuentro Nacional convocado por el Presidente. 
Figura 1: Aprobación de Evo Morales como Presidente de la República, Enero-Diciembre 2011

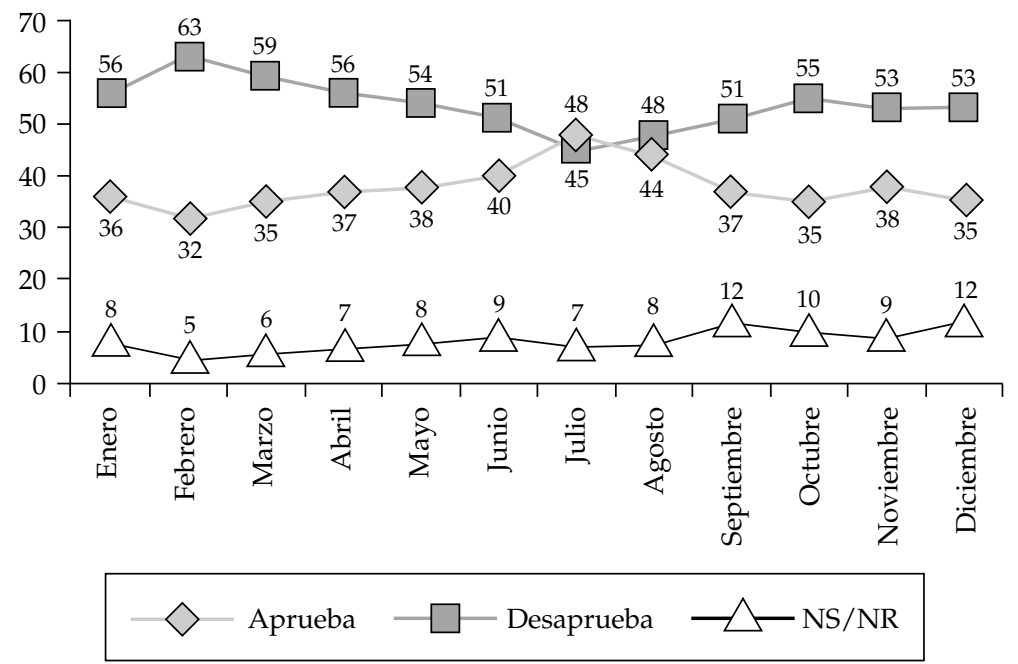

Fuente: http:/ / eju.tv/2011/12/encuesta-nacional-evo-55-de-cada-100-lo-reprueban-revilla-tieneapoyo-del-69-de-los-paceos/

\section{COYUNTURA INTERNACIONAL}

Las relaciones del gobierno del presidente Evo Morales con algunos países vecinos sufrieron variaciones a lo largo del 2011. Las relaciones con Perú han mejorado considerablemente desde la llegada de Ollanta Humala a la presidencia de ese país en julio de 2011. Ambos mandatarios tuvieron varios encuentros amistosos, en uno de los cuales se ratificó la alianza de integración bilateral y el apoyo del Presidente peruano a la demanda marítima boliviana.

Las relaciones entre Bolivia y Paraguay atravesaron por un momento tenso después que la Comisión Nacional de Refugiados ${ }^{15}$ de ese país otorgara el estatus de refugiado a Mario Cossío, Prefecto electo del Departamento de Tarija, tras haber sido destituido de su cargo por presuntos delitos de corrupción. Según Cossío, era víctima de una persecución política y bajo esas circunstancias no podía darse un proceso que garantizara el apego a las leyes. Esa situación incomodó al gobierno y al presidente Morales que a pesar de los intercambios entre el ministro Choquehuanca y su par Héctor Lacognata la situación fue aplacada por el mismo presidente Morales, quien manifestó que esta situación no afectaría su relación con el presidente Fernando Lugo.

El diálogo sin condiciones y la agenda de los 13 puntos entre Chile y Bolivia se vieron opacados por varios hechos. El primero, fue el drástico cambio del gobierno de Evo 
Morales sobre la intención de presentar una demanda ante la Corte Internacional de La Haya para lograr el acceso soberano al mar. El gobierno a través del canciller David Choquehuanca presentó la demanda marítima ante la 41 Asamblea General de la OEA, para "iniciar de inmediato una negociación bilateral concreta, factible y útil". La réplica del canciller chileno, Alfredo Moreno, cerró las puertas a un diálogo fuera del "ordenamiento jurídico internacional", y de "dar a un acceso soberano al océano Pacífico y menos aun sin compensaciones". ${ }^{16}$ Morales llevó su petición de acceso soberano al Pacífico hasta la Asamblea de las Naciones Unidas, quien tuvo la respuesta al día siguiente. El presidente Sebastián Piñera manifestó que entre estos dos países "no hay asuntos territoriales bilaterales pendientes". La demanda formal ante la Corte internacional no se ha realizado hasta la fecha.

El segundo, fue a raíz de la detención del ex jefe antidrogas y director del Centro de Inteligencia del Ministerio de Gobierno en 2010 (general en retiro) René Sanabria en Panamá, cuando en un complejo operativo se detuvo en Arica un contenedor de zinc que tenía un cargamento de 144 kilos de cocaína. ${ }^{17} \mathrm{El}$ presidente Morales reclamó al gobierno chileno que se debió informar sobre el caso del cargamento para tomar acciones internamente. Los ex cancilleres bolivianos Armando Loaiza y Javier Murillo coincidieron en manifestar que este caso afectó la confianza con ese país. La detención de 14 militares bolivianos en territorio chileno en dos autos con placas de ese país también afectó el diálogo entre los dos países. Los militares detenidos fueron expulsados de Chile y a pocos días de su llegada, Evo Morales los condecoró y ascendió. ${ }^{18}$

El cuarto hecho fue la afirmación del ministro de Defensa chileno Andrés Allamand quien dijo que las "Fuerzas Armadas prestigiadas, profesionales y preparadas, [que] están en condiciones de hacer respetar los tratados internacionales y de cautelar adecuadamente la soberanía y la integridad territorial de Chile" ${ }^{19}{ }^{19}$ declaraciones que despertaron preocupación y recelo en el gobierno boliviano.

El tema marítimo sigue siendo el punto de desencuentro entre Bolivia y Chile, pero, a pesar de ello, ambos países siguen trabajando en otras áreas (intercambio de información de aduanas, el tema del libre tránsito en puertos de Arica y Antofagasta, los acuerdos de integración entre municipios de las zonas fronterizas de Bolivia, Chile y Perú).

El hecho sobresaliente fue la normalización de las relaciones de cooperación entre Estados Unidos y Bolivia en noviembre del 2011, ${ }^{20}$ tras la firma de un acuerdo macro entre el vicecanciller de Bolivia y la subsecretaría de Estado para la Democracia y Asuntos Globales de los Estados Unidos. El acuerdo contempla las áreas tradicionales de la

La Nación 7 de junio de 2011 [En línea] http:/ / www.lanacion.cl/mar-bolivia-demanda-intervencion-de-laoea-y-chile-desestima-esa-posibilidad/noticias/2011-06-07/195210.html

17 El Deber 16 de marzo de 2011 [En línea] http:/ / www.eldeber.com.bo/vernotaseguridad.php?id=110315234743
18 Mercurio Online 24 de junio de 2011 [En línea] http:/ / www.emol.com/noticias/internacional/2011/06/24/489023/ evo-morales-condecora-y-asciende-a-los-14-militares-detenidos-en-chile.html

19 Mercurio Online 30 de junio de 2011. http://www.emol.com/noticias/nacional/2011/05/30/484535/ministroallamand-advierte-a-bolivia-ffaa-estan-en-condiciones-de-hacer-respetar-los-tratados.html.

20 Véase Mokvist Uggla, Annika. 2010, “Bolivia, un Año de Consolidación”. Revista de Ciencia Política 30 (2), pág. 203. 
cooperación norteamericana a Bolivia e incluye la cooperación contra la producción y el tráfico ilícito de estupefacientes.

El diálogo reabierto con los Estados Unidos posibilitó la formación de un acuerdo tripartido entre Bolivia, Brasil y Estados Unidos para la lucha contra el tráfico de drogas e incluye el control de producción excedentaria de coca en las zonas no tradicionales. Este acuerdo deberá ser aprobado en los tres países. Bolivia recibirá apoyo de Estados Unidos para la compra de equipos, Brasil proveerá de imágenes satelitales para ser compartidas con los otros dos países.

La relación con Argentina y Brasil y con los miembros del Alba, especialmente con Venezuela, se ha mantenido sin alteraciones durante este año.

\section{1. ¿Reforma del Poder Judicial vía voto popular?}

Las elecciones de los altos magistrados por voto popular es un hecho singular en América Latina. La intención de la elección de los magistrados de los Tribunales Supremo de Justicia, Constitucional, Agroambiental y Consejo de la Magistratura según el presidente Evo Morales era separar los intereses político-partidarios con que fueron elegidos los magistrados antes de la entrada en vigencia de la nueva Constitución Política de Estado Plurinacional de Bolivia.

Este proceso desde su inicio tuvo una serie de observaciones que desvirtuaron la misma elección. La preselección de 125 de 350 postulantes se realizó en dos comisiones de la Asamblea Plurinacional Legislativa. ${ }^{21}$ La selección de los candidatos debía hacerse por mérito. Según la oposición, había candidatos que no reunían la experiencia para ser magistrados de justicia y no fueron observados por las comisiones; Doria Medina en la época manifestó que "el oficialismo está poniendo a sus jueces, a sus dependientes y amigos". ${ }^{22}$ Muestra de ello fueron las 188 impugnaciones a los postulantes que se dieron en las Cámaras de Diputados y Senadores. No obstante, el Congreso seleccionó y aprobó con dos tercios a los 125 candidatos; según representantes de la oposición los parlamentarios del oficialismo "votaron por consigna sin conocerlos, solamente porque son afines al MAS". ${ }^{23}$

El Tribunal Supremo Electoral (TSE) de prohibir las campañas de los candidatos en los medios de comunicación, fue otro de los hechos que desvirtuó el proceso. TSE fue el encargado de dar a conocer a los candidatos 45 días antes de las elecciones, acción que fue cuestionada por la oposición por la falta de libertad para ejercer el derecho de expresión.

21 Según María Teresa Zegada la preselección de los candidatos en la Asamblea Legislativa Plurinacional no resuelve el problema de la intervención de este poder (Zegada, 2011: 6). El MAS tenía la facultad de definir con su voto la preselección de los candidatos. Con argumentos similares Carlos Toranzo manifestó que el proceso de elección de magistrados no democratiza sino más bien politiza el proceso.

22 http://www.bolivia.com/noticias/autonoticias/DetalleNoticia45308.asp

23 El Día [En línea] http://www.eldia.com.bo/mobile.php?cat=150\&pla=7\&id_articulo=68419 [Consulta: 23-3-2012] 
También se cuestionó la escasa e insuficiente información brindada a la población, según encuestas de opinión la mayoría de la ciudadanía decía no conocer a los candidatos. ${ }^{24}$

La oposición y los colegios de abogados de los distintos departamentos presentaron quejas formales para reencauzar el proceso. No obstante, no tuvieron repercusión en el Congreso. Frente a esta situación los partidos de la oposición iniciaron una campaña en contra. El líder del Movimiento Sin Miedo (MSM), Juan del Granado, inició una campaña por el No a las elecciones, los líderes de Unidad Nacional, Samuel Doria Medina, y el senador del Plan Progreso para Bolivia (PPB-CN), Bernardo Gutiérrez promovieron el Voto Nulo.

La agresión del gobierno a los marchistas que defendían el TIPNIS y su falta de responsabilidad coincidieron para que paralelamente se diera un movimiento en las redes sociales que promovían el voto nulo, no obstante que el grado de penetración de Internet en Bolivia es del 19,6\% per ITU, uno de los más bajos en América Latina, ${ }^{25}$ existió un movimiento por el voto nulo promovido desde las redes sociales. El día de las elecciones los suscritos a esas redes informaron sobre las irregularidades en varios recintos electorales.

El día 16 de octubre de 2011 se realizaron las elecciones para magistrados. Las primeras proyecciones de los resultados mostraron que los votos nulos eran mayores a los votos válidos. Los resultados oficiales finales mostraron que los votos nulos y blancos fueron mayores que los votos válidos, como se puede observar en los resultados expuestos en las tablas 1-4. No obstante, para el presidente Evo Morales y para el vicepresidente Álvaro García Lineras la mayoría simple legitimaba su elección y no fue una derrota para el gobierno, más bien una experiencia de la cual debían extraerse lecciones. Al no existir una oposición al gobierno sino varias oposiciones, los líderes de esos fragmentos de oposición consideraron la victoria contra el oficialismo.

Los resultados de esta elección muestran que el voto no responde necesariamente a las directrices de Evo Morales. Según el análisis del comportamiento del voto realizado por Fernando Mayorga, en las áreas rurales el voto es más afín al gobierno mientras que en las áreas urbanas donde ganó el voto nulo es más crítico (Mayorga, 2011).

\section{Elecciones departamentales y municipales}

La nueva Constitución del Estado Plurinacional de Bolivia y la nueva normativa electoral dentro del marco de los gobiernos autónomos suponen la elección directa y por voto mayoritario para gobernadores a nivel departamental (9 en total) y para alcaldes a nivel municipal (337 en total). La elección para los asambleístas departamentales es mixta, por mayoría simple y por sistema proporcional, al que se incluye la elección especial de asambleístas indígenas según sus usos y costumbres en algunos departamentos; este

24 http:/ / eju.tv/2011/09/92-de-la-gente-no-conoce-a-candidatos-a-las-judiciales-en-bolivia / según la encuesta de Ipsos Apoyo el 98\% de la población de las poblaciones de La Paz, El Alto, Cochabamba y Santa Cruz decían no conocer o solo conocen a uno de los candidatos.

25 http://www.internetworldstats.com/south.htm\#bo 
Tabla 1: Cómputo nacional - Tribunal Agroambiental

\begin{tabular}{lcc}
\hline Ciudadanos inscritos & 5.243 .375 & $100,00 \%$ \\
\hline Votos emitidos & 4.177 .470 & $79,67 \%$ \\
Votos válidos & 1.768 .576 & $42,34 \%$ \\
Votos nulos & 1.779 .425 & $42,60 \%$ \\
Votos en blanco & 629.469 & $15,07 \%$ \\
\hline
\end{tabular}

Tabla 2: Cómputo nacional - Consejo de la Magistratura

\begin{tabular}{lcc}
\hline Ciudadanos inscritos & 5.243 .375 & $100,00 \%$ \\
\hline Votos emitidos & 4.172 .416 & $79,58 \%$ \\
Votos válidos & 1.752 .010 & $41,99 \%$ \\
Votos nulos & 1.760 .789 & $42,20 \%$ \\
Votos en blanco & 659.617 & $15,81 \%$ \\
\hline
\end{tabular}

Tabla 3: Cómputo nacional - Tribunal Constitucional Plurinacional

\begin{tabular}{lcc}
\hline Ciudadanos inscritos & 5.243 .375 & $100,00 \%$ \\
\hline Votos emitidos & 4.176 .549 & $79,65 \%$ \\
Votos válidos & 1.758 .283 & $42,10 \%$ \\
Votos nulos & 1.838 .903 & $44,03 \%$ \\
Votos en blanco & 579.363 & $13,87 \%$ \\
\hline
\end{tabular}

Fuente: Tribunal Supremo Electoral, Acta de Cómputo Nacional. Elección de Autoridades del Órgano Judicial y Tribunal Constitucional Plurinacional, 16 de octubre de 2011. http:/ /www.oep.org.bo/

Tabla 4: Tribunal Supremo de Justicia

\begin{tabular}{lcc}
\hline Area Urbana & Hombres & Mujeres \\
\hline Votos válidos & $32,12 \%$ & $31,76 \%$ \\
Votos nulos & $48 \%$ & $47,50 \%$ \\
Votos en blanco & $19,88 \%$ & 20,74 \\
\hline Area rural & Hombres & Mujeres \\
\hline Votos válidos & 47,63 & $46,67 \%$ \\
Votos nulos & 24,74 & $24,25 \%$ \\
Votos en blanco & $27,73 \%$ & $29,08 \%$ \\
\hline
\end{tabular}

Fuente: Lorenzo, G. Angel. 2011. “Elecciones judiciales en el Estado Plurinacional de Bolivia III. El resultado Final". En Revista Andina de Estudios Políticos (10). 
último es inédito en la historia del país. Los concejales municipales son asignados por sistema proporcional y el voto se da a una sola lista.

Bajo este nuevo sistema de elección se dieron las elecciones para las gobernaciones y para las alcaldías el 4 de abril del 2010. El partido del presidente Morales logró conquistar seis de las nueve gobernaciones; los únicos líderes locales que lograron ganar a los candidatos del MAS fueron Rubén Costas en el departamento de Santa Cruz, Mario Cossío en Tarija y Ernesto Suárez en el Beni.

Los resultados de las elecciones para gobernadores y asambleístas departamentales mostraron los límites de los nuevos partidos. El MAS sin lugar a dudas fue el único partido con alcance nacional; muy por debajo se encuentra el Movimiento Sin Miedo (MSM), de Juan del Granado, que si bien no logró obtener ninguna gobernación presentó candidatos en seis de los nueve departamentos.

A pesar del gran triunfo del MAS, su caudal electoral se redujo en comparación con las elecciones de 2009. En esas elecciones Evo Morales y el MAS conquistaron 2.943.209 votos a nivel nacional, ${ }^{26}$ mientras que en las elecciones para gobernadores el MAS obtuvo 1.870.652 votos. Esto se debe en gran parte a la multiplicidad de fuerzas locales construidas en torno a líderes locales que se presentaron a las elecciones municipales, las que lograron reducir los votos al partido oficialista. También hubo mucho descontento de parte de las organizaciones sindicales, aliadas de Evo Morales, por no ser consideradas como candidatos; algunos mencionaron que en la selección de los candidatos del MAS funcionó el "dedazo, compadrazgo y la imposición". ${ }^{27}$

Tabla 5: Departamento Partido Candidato Electo Total, Votos Válidos (\%)

\begin{tabular}{lllcc}
\hline Departamento & \multicolumn{1}{c}{ Partido } & Gobernador electo & $\begin{array}{c}\text { Votos } \\
\text { obtenidos }\end{array}$ & $\begin{array}{c}\text { Porcentaje de los } \\
\text { votos válidos }\end{array}$ \\
\hline Chuquisaca & MAS-IPSP & Esteban Uriquizo & 109.270 & 53,60 \\
La Paz & MAS-IPSP & César Cocarico & 534.563 & 50,00 \\
Cochabamba & MAS-IPSP & Edmundo Novillo & 415.245 & 61,90 \\
Oruro & MAS-IPSP & Santos Tito & 107.576 & 59,60 \\
Potosí & MAS-IPSP & Félix Gonzales & 163.989 & 66,80 \\
Tarija & CAMINO AL CAMBIO & Mario Cossío & 97.726 & 48,90 \\
Santa Cruz & VERDES & Rubén Costas & 51.537 & 52,60 \\
Beni & PRIMERO & Ernesto Suárez & 64.055 & 42,50 \\
Pando & MAS-IPSP & Adolfo Flores & 17.192 & 49,70 \\
\hline
\end{tabular}

Fuente: Diálogos en Democracia, Año 5 No. 1, 9 de mayo de 2010. Pág. 4. 
Los resultados de las votaciones para alcaldes municipales y para concejales dieron resultados positivos para el partido de Evo Morales; los candidatos del MAS ganaron 228 alcaldías en todo el territorio nacional. El MSM logró 21 alcaldías en nueve departamentos (Véase tabla 6).

A pesar de que en estas elecciones Evo Morales jugó un papel importante haciendo campaña para atraer el voto hacia su partido, en la ciudad de La Paz y en la ciudad de Oruro los candidatos del MAS fueron derrotados por el MSM. La gestión de Juan del Granado y su alto favoritirismo lograron traspasar al candidato Revilla.

Los cambios introducidos con la nueva Constitución tenían el propósito de dar mayor legitimidad y representatividad a las autoridades electas y también dotar de una mayor estabilidad a los municipios. Sin embargo, desde la elección de 2010 existe una inestabilidad

Tabla 6: Alcaldes electos por departamento y por fuerza política

\begin{tabular}{|c|c|c|c|c|c|c|c|c|c|c|}
\hline Departamento & $\sum_{i}^{\infty}$ & $\sum_{\sum}^{\infty}$ & $\frac{d}{0}$ & : & $\hat{U}$ & $\underset{\mathbb{I}}{\mathbb{1}}$ & $\sum_{i}^{\infty}$ & 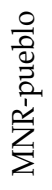 & Otra fuerza & 胥 \\
\hline Beni & 8 & & & 8 & & & & 3 & & 19 \\
\hline Chuquisaca & 23 & 3 & & & & & & & 3 (UDER, NA-C, PAIS) & 29 \\
\hline Cochabamba & 40 & 3 & & & & & & & 4 (ARI, IMU, PUN, UNE) & 47 \\
\hline La Paz & 58 & 8 & & & & & 6 & & $\begin{array}{l}13 \text { (2 PASP, } 2 \text { ADEPCOCA, } \\
\text { CAOSAM, WATUQUIM TS, } \\
\text { TP-A, CUMI, CAOTM, MCP- } \\
\text { NG, FPV, NOS) }\end{array}$ & 85 \\
\hline Oruro & 31 & 3 & & & & & & & 1 (AYNI & 35 \\
\hline Pando & 6 & 4 & & & 9 & & & & & 15 \\
\hline Potosí & 34 & 1 & & & & & & & 2 (PNP, AS) & 40 \\
\hline Santa Cruz & 23 & & 15 & & & 3 & & & $\begin{array}{l}14 \text { (2 OICH, LIDER, SPT, } \\
\text { MANOS, VOCES, MATI-CO, } \\
\text { CHINO, GH, NEGRO, PP, } \\
\text { SAN, SOL, TODOS) }\end{array}$ & 56 \\
\hline Tarija & 5 & & & & & & & & $\begin{array}{l}6 \text { (UNIR, CC, MAR, ARO, PAN, } \\
\text { RHP) }\end{array}$ & 11 \\
\hline Total & 228 & 22 & 15 & 8 & 9 & 3 & 6 & 3 & 43 & 337 \\
\hline
\end{tabular}

Fuente: Boletín de Análisis No 9. Análisis de las Elecciones Municipales 2010. FAM - Bolivia. En Línea http:/ / www.siam.fam.bo/documentos/bolet\%C3\%ADn\%20Nro.\%209.pdf 
de las autoridades por las destituciones tras haber sido acusadas formalmente por el manejo indebido de los recursos económicos públicos. ${ }^{28}$ Estas acusaciones en todos los casos, a excepción de uno, estuvieron dirigidas contra los gobernadores y alcaldes de la oposición. El gobernador por Tarija, Mario Cossío, en diciembre de 2010 fue suspendido de su cargo por presuntos actos de corrupción; un año más tarde en diciembre del 2011 el prefecto de Beni Ernesto Suárez fue suspendido por la misma causa. Cerca de ocho alcaldes electos acusados fueron suspendidos temporalmente de su cargo y en tres casos se llamó a nuevas elecciones para 2011.

De los ocho casos los alcaldes de Sucre y Quillacollo renunciaron a sus puestos y se llamó a elecciones en Sucre (Chuquisaca), Quillacollo (Cochabamba) y Pazña (Oruro). En las elecciones del 18 de diciembre de 2011 los candidatos opositores al MAS ganaron en Sucre y Quillacollo, solo en Pazña el MAS ganó la contienda electoral.

Tabla 7(a-c): Elecciones municipales 18 de diciembre de 2011

\begin{tabular}{lrrlrlllr}
\hline \multicolumn{2}{l}{ Tabla 6 ${ }^{2}$. Sucre (Chuquisaca) } & \multicolumn{2}{l}{ Tabla 6b. Quillacollo (Cochabamba) } & \multicolumn{3}{c}{ Tabla 6c. Pazña (Oruro) } \\
\hline MSM & 2,579 & $2,40 \%$ & MSM & 13,261 & $25,10 \%$ & MSM & 514 & $30,20 \%$ \\
C.S.T. & 1,787 & $1,60 \%$ & UNE & 20,043 & $38,00 \%$ & MAS IPSP & 1186 & $69,80 \%$ \\
Unidad País & 5,718 & $5,20 \%$ & MAS IPSP & 19,477 & $36,90 \%$ & Total: & 1,700 & $100,00 \%$ \\
M-25 & 7,027 & $6,40 \%$ & Total: & 52,781 & $100,00 \%$ & Válidos: & 1,700 & $88,96 \%$ \\
LIDER & 50,614 & $46,30 \%$ & Válidos: & 52,781 & $90,24 \%$ & Blancos: & 58 & $3,04 \%$ \\
MAS -IPSP & 41,703 & $38,10 \%$ & Blancos: & 748 & $1,28 \%$ & Nulos: & 153 & $8,01 \%$ \\
Total: & 109,428 & $100,00 \%$ & Nulos: & 4,960 & $8,48 \%$ & Emitidos: & 1,911 & \\
Blancos: & 1,469 & $90,57 \%$ & Emitidos: & 58,489 & & Inscritos: & 2,747 & \\
Nulos: & 9,927 & $1,22 \%$ & Inscritos: & 82,433 & & Participación & $69,57 \%$ & \\
Emitidos: & 120,824 & $8,22 \%$ & Participación & $70,95 \%$ & & & & \\
Inscritos: & 162,344 & & & & & & & \\
Participación & $74.42 \%$ & & & & & & & \\
\hline
\end{tabular}

Fuentes: 6 a .http://www.oep.org.bo/oep/archivos/elecciones2011/Reporte_chuquisaca_Final.pdf, 6b.http://www.oep.org.bo/oep/archivos/elecciones2011/ReporteAlcalde-CBA-19122011-1524. pdf 6c. http://www.oep.org.bo/oep/archivos/elecciones2011/ReporteAlcalde-ORU.pdf

28 La nueva Ley de Municipalidades en su artículo 144 sanciona: que “ Gobernadoras, Gobernadores, Alcaldesas y Alcaldes, Máxima Autoridad Ejecutiva Regional, Asambleístas Departamentales y Regionales, Concejalas y Concejales de las entidades territoriales autónomas podrán ser suspendidas y suspendidos de manera temporal en el ejercicio de su cargo cuando se dicte en su contra Acusación Formal". La inclusión de este artículo se basa en la crítica a la inmunidad y a los juicios de corte por los que pasaban los alcaldes con la legislación anterior. Con la nueva normativa solo el hecho de que exista una acusación formal, la que puede ser comprobada o no, basta para la destitución. La ley no contempla los daños ni resarcimiento, solo la reincorporación del "acusado". En el caso de comprobarse la acusación se llama nuevamente a elecciones para ese puesto. Para mayor referencias véase: http://www.gobernabilidad.org.bo/component/content/ article/2-noticias/362-ley-marco-de-autonomias-y-descentralizacion-de-bolivia 


\section{Poder Ejecutivo}

El presidente Evo Morales durante 2011 tuvo que administrar dos crisis ministeriales. La primera modificación de su gabinete se dio el 24 de enero de 2011 tras la renuncia del gabinete en pleno debido a la demanda de los distintos sectores sociales que pedían la renuncia de los ministros a causa del gasolinazo. En esa ocasión Evo Morales ratificó la confianza a sus ministros y sólo realizó tres cambios.

A fines de septiembre, a causa de la represión a los marchistas del TIPNIS, el ministro de Gobierno, Sacha Llorenti, y la ministra de Defensa renunciaron a su cargo.

\section{Gabinete Ministerial 2011}

\begin{tabular}{ll}
\hline Ministro de Relaciones Internacionales & $\begin{array}{l}\text { David Choquehuanca } \\
\text { Ministro de la Presidencia }\end{array}$ \\
& $\begin{array}{l}\text { Oscar Coca (reunicia) 15-Junio-2011 } \\
\text { Carlos Romero Ballivián (nominado el 15-junio 2011). } \\
\text { Independiente, abogado } \\
\text { Sacha Llorenti (1972) del 23 enero 2010 al 27 septiembre } \\
\text { Ministro de Gobierno }\end{array}$ \\
& $\begin{array}{l}\text { Derechos Humanos) } \\
\text { Wilfredo David Chávez Serrano (del 27 de septiembre 2011) }\end{array}$ \\
& Rubén Saavedra Soto (cambio 6 de abril) \\
Ministro de Defensa & María Chacón Rendón (del 6 de abril de 2011 al 26 de \\
& septiembre de 2011). Independiente, abogada y politóloga \\
& Rubén Saavedra (del 26 de septiembre de 2011) \\
Ministra de Defensa Legal del Estado & Elizabeth Arismendi* \\
Ministra de Planificación del Desarrollo & Viviana Caro* \\
Ministro de Economía y Finanzas & Luis Alberto Arce Catacora
\end{tabular}

Ministro de Hidrocarburos y Energía

José Luis Gutiérrez (1953)

Independiente (del 23 de enero de 2011). Ingeniero Químico

Ministra de Desarrollo Productivo y

Economía Plural

Ana Teresa Morales (del 23 de enero de 2011). Independiente, Master en Desarrollo

Ministro de Obras Públicas, Servicios y Walter Delgadillo*

Vivienda

Ministro de Minería y Metalurgia

José Pimentel*

Ministra de Justicia

Nilda Copa*

Ministra de Trabajo, Empleo y

Previsión Social

Carmen Trujillo* (1968). Sindicato Fabriles Trabajadora sector Industrial

Félix Rojas del 16-febrero al 6-junio-2011 MAS

Daniel Santalla Torres, 6-junio-2011 ex Secretario general de la COB Lic. en Ciencias Políticas

Ministra de Salud y Deportes

Nila Heredia*

Ministra de Medio Ambiente y Agua

Julieta Mabel Monje (del 23 de enero de 2011). Trabajó con juntas vecinales de la ciudad de El Alto, Abogada 


\begin{tabular}{ll}
\hline $\begin{array}{l}\text { Ministro de Educación } \\
\text { Ministra de Desarrollo Rural y Tierras }\end{array}$ & $\begin{array}{l}\text { Roberto Aguilar* } \\
\text { Nemesia Achacollo* } \\
\text { Ministro de Autonomías }\end{array}$ \\
$\begin{array}{l}\text { Carlos Romero* 15-junio-2011 } \\
\text { Claudia Peña 15-junio-2011 }\end{array}$ \\
$\begin{array}{l}\text { Ministra de Transparencia y } \\
\text { Minticorrupción }\end{array}$ & Nardy Suxo* \\
\hline
\end{tabular}

* Ratificados en su puesto el 23 de enero del 2011.

En la composición de los ministerios el presidente Morales ha tratado de incorporar a personalidades que puedan servir de vínculo con los diferentes sectores de la sociedad. Es por eso que en los cambios ministeriales realizados durante el año 2011 el Presidente nominó a personalidades relacionadas con el sector sindical como son los casos de Carmen Trujillo, Daniel Santalla Torres y Julieta Mabel Monje, mientras que en los ministerios de Hidrocarburos y Energía, Desarrollo Productivo y Economía Plural, nominó a técnicos profesionales afines al proceso de cambio.

El gobierno del presidente Evo Morales se caracteriza por tener una gran autonomía en la decisión sobre las políticas públicas, pero sus acciones siguen los lineamientos estratégicos definidos en el Programa de Gobierno 2010-2015. El Presidente cuenta con el apoyo de los representantes del MAS-IPSP en el Congreso para la aprobación de los proyectos de leyes que son remitidos a la Asamblea Plurinacional. El vicepresidente Álvaro García Lineras como presidente nato del Congreso se constituye en el verdadero canalizador de los proyectos del Ejecutivo en el Congreso. Evo Morales también ha utilizado los decretos presidenciales para cambiar la dirección de una política, como lo fue el DS 748; durante el año 2011 el Presidente emitió 356 decretos supremos. ${ }^{29}$

Con el propósito de relanzar la agenda del gobierno y dar legitimidad y consenso a la misma, en diciembre Evo Morales llamó a un diálogo en el participaron representantes de las gobernaciones y municipios que están bajo la administración del MAS, sindicatos productores de hoja de coca, sindicatos campesinos, trabajadores de empresas estatales, mandos militares, policiales, universidades estatales, un sector de la CONAMAQ y líderes del empresariado nacional. La incorporación del sector privado es un avance importante en la conformación de alianzas entre Estado y sector privado nacional después del impacto que tuvo por las políticas del Presidente hacia el sector privado nacional ${ }^{30}$. A este diálogo no acudieron miembros de la oposición, ni líderes de la COB, ni de la CIDOB.

29 Véase Gaceta Oficial del Estado Plurinacional de Bolivia. [En línea] http://www.gacetaoficialdebolivia. gob.bo/

30 El sector productor de azúcar, exportador de APTEA, Aerosur, los productores de soya, la nacionalización de la fábrica de cemento, para mencionar algunos. 


\section{Poder Legislativo}

Las elecciones generales del $2009^{31}$ dieron como resultado la mayoría de los dos tercios tanto en la Cámara de Diputados como en la Cámara de Senadores para el MAS-IPSP. Los tres partidos representados en el Congreso, el PPB-CN, la UN-CP y la AS no tienen la capacidad para modificar o cambiar los proyectos de leyes, no solo en el plenario cuando se analizan y aprueban los proyectos de leyes ni en las comisiones de ambas Cámaras.

La ruptura del MSM con el Presidente durante las elecciones municipales significó la pérdida de tres de los cuatro representantes. Pero no ha significado la pérdida de la larga mayoría con la que cuenta en la Cámara Baja.

La intervención del presidente Morales en el Congreso se reflejó con la elección de las directivas de ambas Cámaras. Los parlamentarios del MAS en una reunión en la que participó el presidente Evo Morales decidieron mantener la conformación de las presidencias de ambas Cámaras. Siguiendo ese lineamiento los representantes masistas ratificaron a Héctor Arce Zaconeta como presidente de la Cámara de Diputados y René Martínez presidente de la Cámara de Senadores. Los puestos directivos de la Cámara de Senadores estuvieron controlados por los representantes masistas. De las 10 comisiones que existen en la Cámara de Senadores, ocho fueron dirigidas por el MAS y dos por minoría que corresponde a la oposición.

En la Cámara de Diputados la segunda vicepresidencia recayó sobre Jorge Antonio Flores de PPB; la primera y segunda secretaría están controladas por el MAS; la tercera secretaría recayó en Víctor Hugo Zamora, representante de $\mathrm{CN}$, y la cuarta secretaría recayó en el representante de Potosí Angel Cortez (AS). De las 12 comisiones que hay en esta Cámara, el MAS controla 10 y la oposición 2 (PPB-CN). En esta Cámara el principio de representación por minoría solo se aplica al segundo partido con mayor representación Convergencia Nacional (28\%), pero no a los otros dos partidos minoritarios representados en el Congreso (Frente de Unidad Nacional y AS, tres y dos diputados respectivamente).

De enero de 2011 al 29 de diciembre de 2011 el Congreso sancionó 129 leyes. En la Cámara de Senadores se presentaron 152 proyectos de ley y en la Cámara de Diputados 841 proyectos, de los cuales 88 fueron presentados por el Ejecutivo y 30 por las entidades territoriales autónomas.

La Cámara de Diputados ejerció su función de fiscalización, solicitó 1.883 Peticiones de Informe Escrito (PIE), 1.345 tuvieron respuesta; la mayor parte de las PIES fueron solicitadas al Poder Ejecutivo. También realizaron 52 Peticiones de Informe Oral (PIO), de las cuales 34 fueron verificadas.

\section{Consideraciones finales}

Este año analizado ha reportado resultados positivos para la economía que sigue dependiendo de la exportación del gas y de los minerales. Sin embargo, esta dependencia 
también muestra los límites de su crecimiento sin la inversión en estos sectores. La inversión pública en las empresas estatales no extractivas aún no está dando los resultados esperados.

Este año también se caracteriza por el surgimiento de conflictos con aliados al gobierno del Presidente y por la falta de celeridad en la resolución de los conflictos, lo que afectó significativamente la imagen del gobierno. El Presidente y el MAS cuentan con el control del Poder Ejecutivo y el Legislativo; sin una oposición político-partidaria que le haga frente en el Congreso tuvo que volver a la política del diálogo fuera del ámbito institucional para reforzar y legitimar con sus aliados la Agenda del Gobierno. Esto muestra que a pesar de los cambios introducidos en el Poder Legislativo, los representantes no están canalizando ni logrando articular las demandas de sus representados.

Las elecciones para magistrados del Poder Judicial y los resultados mostraron el descontento por la forma que se llevó el proceso. La forma de selección de los candidatos, la falta de información sobre los mismos y las circunstancias en las que se dieron las elecciones (el conflicto del TIPNIS) desvirtuaron el proceso. Desde la perspectiva del TSE, los candidatos que obtuvieron el voto mayoritario son magistrados democráticamente electos y por consiguiente gozan de legalidad, sin embargo la legitimidad de los mismos, que fue cuestionada por el voto nulo y en blanco, dependerá de su desempeño en sus respectivas instituciones donde toman posición.

El MSM y la UN son dos partidos que compiten entre sí y al mismo tiempo se oponen separadamente al gobierno, lo hicieron durante las elecciones judiciales. Es difícil que estos dos partidos que se dividen la simpatía de la ciudadanía en la ciudad de La Paz puedan articular una oposición que logre competir contra el MAS en un futuro cercano. Mientras tanto el presidente Morales sin esta oposición puede rearticular sus alianzas con los sectores sociales con llamados a diálogos nacionales como el de diciembre de 2011.

\section{REFERENCIAS}

Arias, I. 2011. "El Estado de las Empresas del Estado", en Coloquios Económicos. Fundación Milenio (23). Banco Central de Bolivia. 2011. "Reporte Semestral de Saldos y Flujos del Capital Privado Extranjero en Bolivia". Junio 2011. [En línea] http://www.bcb.gob.bo/webdocs/2011/SalaDePrensa/otros/ Reporte\%20I-2011\%20RSFVPE.pdf [Consulta: 30-2-2012]

Bolivia.com periódico onlinehttp://www.bolivia.com/noticias/autonoticias/DetalleNoticia45308.asp Cámara Nacional de Comercio. 2011. "Dos Años del Segundo Periodo del Gobierno de Evo Morales y el Compromiso de la Implementación de una Agenda Económica". Enero de 2012. [En línea] http:// www.boliviacomercio.org.bo/cnc/Documentos/NP201202Enero.pdf. [Consulta: 30-2-2012]

Correo del Sur 30 de junio de 2011. [En línea] http:/ / correodelsur.com/2011/0630/75.php [Consulta: 20-2-2012]

Correo del Sur 30 de junio de 2011. [En línea] http://correodelsur.com/2011/0630/75.php [Consulta: 20-2-2012]

Ministerio de Desarrollo Productivo y Economía Plural. "Las Empresas Estatales en el Nuevo Modelo Económico de Bolivia". [En línea] http://medios.economiayfinanzas.gob.bo/MH/documentos/ Materiales_UCS/Libros/Libro_empresas.pdf [Consulta: 30-2-2012]

El Deber 16 de marzo de 2011 [En línea] http:/ / www.eldeber.com.bo/vernotaseguridad.php?id=110315234743 El Día [En línea] http://www.eldia.com.bo/mobile.php?cat=150\&pla=7\&id_articulo=68419 [Consulta: 23-3-2012] 
Eju TV. Periódico online. http:/ / eju.tv/2011/09/92-de-la-gente-no-conoce-a-candidatos-a-las-judicialesen-bolivia/

El Mundo 31 de diciembre de 2010. [En línea] http:/ / www.elmundo.com.bo/Secundarianew.asp?edicio $\mathrm{n}=31 / 12 / 2010 \&$ Tipo=Politica\&Cod=10944 [Consulta: $20-2-2012]$

El Sol 27 de septiembre de 2011. [En línea] http://www.elsol.com.bo/index.php?c=pol\%EDtica\&articul o=Repudio-por-el---Tipnis\&cat=150\&pla=3\&id_articulo=21139

FAM-Bolivia. 2010. “Análisis de las Elecciones Municipales 2010”. Boletín de Análisis. La Paz: FAM.

Fundación Milenio 2012. "Informe de Coyuntura Nacional". N 132. Febrero 2012.

Fundación Tierra. 2011. “Nuestra Tierra” [En línea]. http://marcha.ftierra.org/index.php?option=com_co ntent\&view=article\&id=638:rair\&catid=35:news . [Consulta: 3-12-2011]

Gaceta Oficial del Estado Plurinacional de Bolivia. "Decreto Supremo 748". [En línea] http:/ / gacetaoficialdebolivia.gob.bo/normas/view/138884 [Consulta: 13-2-2012]

Gaceta Oficial del Estado Plurinacional de Bolivia. [En línea] http:/ /www.gacetaoficialdebolivia.gob.bo/

La Nación 7 de junio de 2011 [En línea] http:/ / www.lanacion.cl/mar-bolivia-demanda-intervencion-dela-oea-y-chile-desestima-esa-posibilidad/noticias/2011-06-07/195210.html

Los Tiempos 2 de enero del 2011. [En línea] http://www.lostiempos.com/diario/actualidad/ economia/20110102/morales-el-cambio-de-ministros-es-mi-atribucion_106671_208787.html [Consulta: 20-2-2012]

Los Tiempos 31 de agosto de 2011. [En línea] http://www.lostiempos.com/diario/actualidad/ economia/20110831/colonizadores-afirman-que-no-dejaran-pasar-a-la-marcha-del_139962_287097.html

Mercurio Online24 dejunio de 2011 [Enlínea] http:/ /www.emol.com/noticias/internacional/2011/06/24/489023/ evo-morales-condecora-y-asciende-a-los-14-militares-detenidos-en-chile.html

Mercurio Online 30 de junio de 2011. http:/ /www.emol.com/noticias/nacional/2011/05/30/484535/ ministro-allamand-advierte-a-bolivia-ffaa-estan-en-condiciones-de-hacer-respetar-los-tratados.html.

Ministerio de Economía y Finanzas Públicas. 2011. “Indicadores Macroeconómicos". [En línea] http:// www.economiayfinanzas.gob.bo/index.php?opcion=com_indicadores\&ver=indicadores\&idc $=564$, [Consulta: 13-2-2012]

Mokvist Uggla, A. 2010, “Bolivia un Año de Consolidación". Revista de Ciencia Política 30 (2).

Zegada, T. 2011. "Democratización de la Justicia en Bolivia? La inédita elección de magistrados por voto directo". En Conversatorio de Análisis Político. La Paz: Fundación Boliviana para la Democracia Multipartidaria y PNUD.

La Prensa Online. 11 de abril de 2010.

Grace I. Deheza. Tiene un Ph.D. en Ciencias Políticas otorgado por el Instituto Universitario Europeo, Florencia, Italia. Fue profesora titular en la Universidad Mayor de San Andrés y docente invitada en la Universidad Católica Bolivia, Escuela de Guerra Naval, La Paz Bolivia. Actualmente es consultora de Newlink Research.

Email: gracedeheza@yahoo.com. 